\title{
Long-Term Stabilization of Place Cell Remapping Produced by a Fearful Experience
}

\author{
Melissa E. Wang, ${ }^{1}$ Ellen G. Wann, ${ }^{2}$ Robin K. Yuan, ${ }^{2}$ Manuel M. Ramos Álvarez, ${ }^{3}$ Squire M. Stead, ${ }^{4}$ and Isabel A. Muzzio ${ }^{2}$ \\ ${ }^{1}$ Neuroscience Graduate Group, ${ }^{2}$ Department of Psychology, University of Pennsylvania, Philadelphia, Pennsylvania 19104, ${ }^{3}$ University of Jaen, 23071 Jaen, \\ Spain, and ${ }^{4}$ Department of Neurology, Mayo Clinic, Rochester, Minnesota 55905
}

Fear is an emotional response to danger that is highly conserved throughout evolution because it is critical for survival. Accordingly, episodic memory for fearful locations is widely studied using contextual fear conditioning, a hippocampus-dependent task (Kim and Fanselow, 1992; Phillips and LeDoux, 1992). The hippocampus has been implicated in episodic emotional memory and is thought to integrate emotional stimuli within a spatial framework. Physiological evidence supporting the role of the hippocampus in contextual fear indicates that pyramidal cells in this region, which fire in specific locations as an animal moves through an environment, shift their preferred firing locations shortly after the presentation of an aversive stimulus (Moita et al., 2004). However, the long-term physiological mechanisms through which emotional memories are encoded by the hippocampus are unknown. Here we show that during and directly after a fearful experience, new hippocampal representations are established and persist in the long term. We recorded from the same place cells in mouse hippocampal area CA1 over several days during predator odor contextual fear conditioning and found that a subset of cells changed their preferred firing locations in response to the fearful stimulus. Furthermore, the newly formed representations of the fearful context stabilized in the long term. Our results demonstrate that place cells respond to the presence of an aversive stimulus, modify their firing patterns during emotional learning, and stabilize a long-term spatial representation in response to a fearful encounter. The persistent nature of these representations may contribute to the enduring quality of emotional memories.

\section{Introduction}

A vast amount of research implicates the hippocampus in the retrieval of episodic memory, and it is thought that this region provides the contextual framework for the encoding of emotional events (Knierim, 2003). The role of the hippocampus in episodic emotional memory is commonly studied using Pavlovian contextual fear conditioning, a hippocampus-dependent task in which a neutral context [conditioned stimulus (CS)] becomes associated with an aversive event [unconditioned stimulus (US)], producing a conditioned response evident when the CS is presented alone (Pavlov, 1927; Kim and Fanselow, 1992; Phillips and LeDoux, 1992).

Physiological evidence implicating the hippocampus in contextual memory comes from the observation that pyramidal cells in this region fire in specific locations (the firing field of the cell) as an animal moves through an environment (O'Keefe and Dostrovsky, 1971). These place cells respond to environmental

Received Feb. 1, 2012; revised Sept. 5, 2012; accepted Sept. 11, 2012.

Author contributions: M.E.W. and I.A.M. designed research; M.E.W., E.G.W., and R.K.Y. performed research; M.M.R.Á. and S.M.S. contributed unpublished reagents/analytic tools; M.E.W. analyzed data; M.E.W. and I.A.M. wrote the paper.

This work was supported by Behavioral and Cognitive Neuroscience Training Grant MH017168 (M.E.W.; T. Abel, principal investigator). We thank Ted Abel, Javier Medina, and Carmen Torres-Bares for their comments on an earlier version of this manuscript. We also thank Charles Addo-Yobo and Linda Yin for their help with behavioral experiments and histology.

The authors declare no competing financial interests.

Correspondence should be addressed to Isabel A. Muzzio, Department of Psychology, 3720 Walnut Street, D5 Solomon Laboratory Building, Philadelphia, PA 19104-6241. E-mail: imuzzio@sas.upenn.edu.

DOI:10.1523/JNEUROSCI.0480-12.2012

Copyright $\odot 2012$ the authors $\quad 0270-6474 / 12 / 3215802-13 \$ 15.00 / 0$ changes through remapping, a property reflected by the tendency of a cell to shift its preferred firing location (for review, see Colgin et al., 2008). Importantly, remapping can be modulated by parameters other than spatial cues (Markus et al., 1995; Wood et al., 1999; Huxter et al., 2003; Kentros et al., 2004; Smith and Mizumori, 2006; Muzzio et al., 2009b), allowing the hippocampus to generate several multimodal representations of a single context. However, under some conditions, place cells display high stability by firing in the same location during consecutive exposures to a particular environment. Since stability requires the same biochemical cascades necessary for memory consolidation and longterm potentiation (Kentros et al., 1998; Rotenberg et al., 2000; Agnihotri et al., 2004), it is thought to be a neural correlate of spatial memory.

One parameter that has been shown to modulate place cell stability in the short term is fear (Moita et al., 2004), yet the physiological correlates of unconditioned and long-term conditioned fear in the hippocampus are unknown. This is in part due to the common use of electric shock as a US, since shock results in electrical noise (Oler et al., 2008) in addition to aggressive defense behavior not conducive to maintaining stable recordings (Ulrich, 1966). Moreover, shock produces high levels of freezing (Blanchard and Blanchard, 1969), a stereotypic response to fear that prevents full exploration of the environment essential for place cell recordings (O'Keefe and Nadel, 1978). Taking advantage of the ethological relevance of predator odors and the moderate conditioned freezing they produce (Takahashi et al., 2007), we developed a novel contextual fear conditioning paradigm using coyote urine. Predator odor has an additional advantage over 
shock in that it is a relatively diffuse fearful stimulus, which ensures that any place cell remapping observed is not related to the precise location of the fearful stimulus. Using this predator odor fear conditioning paradigm, we found that a majority of place cells remapped in response to predator odor exposure, and these newly formed representations stabilized in the long term. These findings may have important implications for understanding the persistence of fearful episodic memories.

\section{Materials and Methods}

Subjects. Male C57BL/6 mice, 2-5 months of age (The Jackson Laboratory), were housed individually on a $12 \mathrm{~h}$ light/dark cycle and allowed access to food and water ad libitum for at least 2 weeks before behavioral experiments. In the behavioral experiments, 25 mice were used in the fear-conditioned group and 21 were used as controls. Of these, seven fear-conditioned and three control animals were also used for cellular recordings. Animal living conditions were consistent with the standard required by the Association for Assessment and Accreditation of Laboratory Animal Care. All experiments were approved by the Institution of Animal Care and Use Committee of the University of Pennsylvania and were performed in accordance with NIH guidelines.

Fear conditioning. Mice were habituated to the training context (a Plexiglas cylinder $35 \mathrm{~cm}$ in diameter with visual cues along the wall) $1 \mathrm{~d}$ before conditioning, and a baseline freezing measure was taken in the same context immediately prior to predator odor exposure (see Fig. 1a). Mice were then exposed to 20 drops of $100 \%$ coyote urine (Maine Outdoor Solutions), presented by saturating a $2.5 \times 2.5 \mathrm{~cm}$ square paper towel placed in the center of the training context. A short-term memory retrieval test was given $1 \mathrm{~h}$ after conditioning, followed by a test session $6 \mathrm{~h}$ later as well as daily long-term memory tests at $24 \mathrm{~h}$ intervals postconditioning. All sessions except the coyote odor exposure lasted $10 \mathrm{~min}$. During these sessions, the paper towel was wetted with water (no odor) to ensure that the context remained the same except for the odor itself. The coyote odor session lasted $4 \mathrm{~min}$, but was extended to $5 \mathrm{~min}$ during electrophysiology experiments to allow for complete sampling of the environment. The control animals were treated in the same manner as the fear-conditioned animals, following the same schedule of context exposures. However, these animals were only exposed to water in place of the predator odor. A single context was used throughout the experiment; long-lasting odor contamination was prevented by scrubbing the apparatus several times with bleach, soap, and water immediately after removal of the paper towel wetted with coyote urine, followed by further cleaning with ethanol. Ethanol was also used for standard cleaning between all sessions, so any odor left by the ethanol was constant throughout the experiment. The training room was aired out with multiple fans for the entire hour in between the coyote session and the $1 \mathrm{~h}$ retention test. During control experiments, the context was treated with the same cleaning regimen for consistency. A subset of fear-conditioned animals $(n=20)$ was tested in a neutral context in addition to the training context in a counterbalanced order. The neutral context, which was located in a different room but was similar to the conditioning context in size, shape, and number of visual cues, was only presented at certain time points to prevent fatigue as a result of excessive exploratory activity.

To obtain consistent predator odor conditioning, a moderately sized conditioning chamber was used to prevent rapid diffusion of the odor. This was important because an overly large context may fail to take on predictive value from a predator odor (Rosen et al., 2008).

Behavioral analysis. All behavioral measures were analyzed using the Limelight tracking system (Coulburn Instruments) and Excel (Microsoft). Freezing was defined as the percentage of time an animal spent immobile using a maximum speed threshold of $0.6 \mathrm{~cm} / \mathrm{s}$, and analyzed using Limelight and Excel. Average speed was calculated excluding time spent freezing. Avoidance was measured as the amount of time spent in the outer ring furthest from the odor when the context was divided by three equally spaced concentric circles. We also measured elongation, since stretch-attend postures, marked by a flat-back position and increase in body length, are the most frequently used measures of defensive risk assessment behavior (Grant and Mackintosh, 1963; Dielenberg and
McGregor, 2001). The threshold for elongation was set at a minimum body length (from nose to base of tail) of $8.8 \mathrm{~cm}$, a parameter that was determined experimentally through observation before analysis with Limelight. All instances in which animals displayed a body length of 8.8 $\mathrm{cm}$ or greater were included in the total percentage of time spent elongated.

Surgery. Mice were anesthetized with a mixture of ketamine (100 mg/ $\mathrm{kg})$ and xylazine $(10 \mathrm{mg} / \mathrm{kg})$ administered intraperitoneally $(0.1 \mathrm{ml} / \mathrm{kg})$. The mice were then placed into a stereotaxic frame in a flat skull position (David Kopf Instruments). Craniotomies were performed at the following coordinates from bregma (in $\mathrm{mm}$ ): $\mathrm{AP},-1.7$; $\mathrm{ML},-1.6$. Drivable six-tetrode microdrives were implanted, with recording electrodes placed directly above the dorsal hippocampus (depth from dura: DV, $-1.0)$. A ground wire was connected to a screw placed on the contralateral side of the skull. The headstages were secured to the animals' skulls with cyanoacrylate and dental cement. Animals were allowed at least 1 full week of recovery before beginning electrophysiological experiments.

Electrophysiology. The headstage was connected to a tethered unity gain amplifier with green and orange light-emitting diodes for tracking the position of the animal's head. The tether cable was connected to a distribution panel, and units were amplified using a 32-channel amplifier (Neuralynx). Electrical signals were amplified between 2500 and 10,000 times and filtered between 400 and $9000 \mathrm{~Hz}$. The amplifier output was digitized at $30.3 \mathrm{kHz}$. The position of the animal and electrophysiological data were recorded by Cheetah Data Acquisition software (Neuralynx) on a HP xw4400 workstation computer. Beginning at least 1 week after surgery, neural activity from each tetrode was screened daily. The search for cells was conducted in a large cylindrical environment different from the one used in behavioral experiments. The electrode bundle was advanced by $15-20 \mu \mathrm{m}$ steps per day; lowering the tetrodes in small steps served to increase the stability of the recordings (Kentros et al., 2004; Muzzio et al., 2009b). Pyramidal cells were identified by their characteristic tendency to fire in complex spikes, bursts of two to seven spikes of decreasing extracellular amplitude that fire at short (5-7 ms) interspike intervals (Ranck, 1973). Once pyramidal cells were located in the hippocampus, individual cells were isolated to facilitate visualization of the cells during the experiments and provide a way to assess recording stability (see below, Data analysis). Experiments were begun only when recordings were stable for at least $18 \mathrm{~h}$. Long-term recordings were considered stable when cells had the same cluster boundaries over two sessions (at least $18 \mathrm{~h}$ apart), and the waveforms obtained from all four wires of a tetrode were identical (see Fig. $2 b$ ).

Histology. Electrode placement was verified after completion of recordings. Animals were anesthetized with a mixture of ketamine (100 $\mathrm{mg} / \mathrm{kg}$ ) and xylazine $(10 \mathrm{mg} / \mathrm{kg})$. Final electrode positions were marked by passing a current $(0.1 \mathrm{~mA}$ for $5 \mathrm{~s})$ through the tetrodes that yielded unit data (53500 Lesion Making Device; Ugo Basile). Transcardial perfusion was performed on the animals with $0.01 \mathrm{~m}$ PBS followed by $10 \%$ formalin (Thermo Fisher Scientific). The brains were removed and fixed at $4^{\circ} \mathrm{C}$ for at least $24 \mathrm{~h}$ in $10 \%$ formalin containing $3 \%$ potassium ferrocyanide (J. T. Baker) for Prussian blue staining. They were then transferred to a $30 \%$ sucrose solution and kept for at least $48 \mathrm{~h}$ at $4^{\circ} \mathrm{C}$ for cryoprotection. Brains were then cryosectioned (30 $\mu \mathrm{m}$, coronal) and Nissl stained with cresyl violet using standard histological procedures (Powers and Clark, 1955).

Data analysis. After completion of the experiments, units were cluster cut and analyzed using MClust software (developed by A. David Redish, University of Minnesota, Minneapolis, MN). Cells were only accepted for analysis if they formed isolated clusters with clear Gaussian ellipses and minimal overlap with surrounding cells and noise, and exhibited long-term recording stability as described above and in previous studies. For long-term recording stability, cells had to exhibit stable waveforms and distinct cluster boundaries overimposed between consecutive sessions. To ensure cluster quality, we also computed isolation distance, a measure of how separated a cluster is from other spikes recorded on the same tetrode (Harris et al., 2001; Schmitzer-Torbert et al., 2005). Since this parameter reflects the radius of the smallest ellipsoid from the center of the cluster under study to noise or other spikes, the variability of this measure for each cell also provided a measure of recording stability. If the 
Table 1. Number of cells recorded per mouse

\begin{tabular}{llcl}
\hline & Animal & No. of cells & $\begin{array}{l}\text { Average of all } \\
\text { long-term correlations }\end{array}$ \\
\hline Fear conditioned & 1 & 4 & $0.49 \pm 0.03$ \\
& 2 & 6 & $0.65 \pm 0.07$ \\
& 3 & 7 & $0.5 \pm 0.04$ \\
& 4 & 6 & $0.48 \pm 0.07$ \\
& 5 & 9 & $0.48 \pm 0.04$ \\
Control & 10 & $-a$ \\
& 7 & 6 & $0.33 \pm 0.03$ \\
& 1 & 4 & $0.34 \pm 0.14$ \\
& 2 & 4 & $0.21 \pm 0.06$ \\
\hline
\end{tabular}

Two mice from the fear-conditioned group ( 6 and 7 ) were included only in the short-term analyses due to poor long-term cluster quality. The average of all long-term correlations was calculated by taking the mean of all the correlations between long-term sessions for all the cells in each animal, starting from $6 \mathrm{~h}$ versus $24 \mathrm{~h}$ through $96 \mathrm{~h}$ versus $120 \mathrm{~h}$. These data show that all animals in the fear-conditioned group displayed long-term correlations higher than those observed in the control group, indicating that our results are consistent across animals. Means \pm SEM are shown.

${ }^{a}$ Cells in these animals were included only in the short-term analyses.

isolation distance of a cluster in a given session was $>2$ SDs above or below the mean across sessions, the cell was not included in the analysis. Additionally, cells that fired $<25$ spikes in each session were excluded from the analysis. In all, 69 cells met our criteria for inclusion: 48 cells from seven fear-conditioned animals and 20 cells from three control animals were included in the analyses (Table 1). Of these, 16 cells from two fear-conditioned animals exhibited poor long-term cluster quality and therefore were only included in the short-term remapping analyses. We were able to record 23 cells from fear-conditioned animals and 10 cells from control animals up to $120 \mathrm{~h}$.

To analyze place fields, two sets of data were generated, one containing the spike rate (total number of spikes in each pixel) and the other containing the total amount of time spent by the animal in each pixel. Dividing the spike array by the time array yielded a spike rate map, a two-dimensional representation of the environment with each pixel color-coded for time-averaged firing rate. Different colors on the map represented differences in firing frequency. The generation of these maps was done with code written in C (S. Matthew Stead, Mayo Clinic, Rochester, MN). Only periods of movement were included in the place field analysis, during which the minimum walking speed was $3 \mathrm{~cm} / \mathrm{s}$. Place field stability was assessed by performing pixel-by-pixel Pearson $\mathrm{R}$ cross-correlations between maps. To calculate the percentage of cells that remapped or remained stable, cells exhibiting correlation values $<0.21$ were considered remapping, and cells with correlation values 0.21 or above were considered stable. This remapping index was obtained by correlating neuronal activity between the training context and a neutral context, and represents the degree of remapping observed between two environments of the same shape and size with different visual cues. To characterize changes in firing rate due to fear conditioning, we analyzed in-field firing rates. A rate change index for each cell was calculated by dividing the difference in firing rates between each session and its preceding session by the sum of the rates ([session - previous session]/[sum]). To determine whether each cell displayed a long-term increase in firing rate relative to preconditioning sessions, we averaged the firing rates of the baseline and habituation sessions and compared this value with the average firing rate of all long-term sessions $(6-120 \mathrm{~h})$ for that cell. If the average value of the long-term sessions was greater than that of the preconditioning sessions, the cell was considered to have shown an increase in firing rate in the long term. Additionally, we analyzed center of mass (COM) shift, coherence, and field size. The COM for each cell was computed by determining the $x$ and $y$ coordinates that corresponded to the spatial location displaying the highest firing rate of the place field of the cell in each trial; COM shift is a parameter that evaluates the displacement of the COM between sessions. Coherence is a measure that evaluates the organization of the field, calculated as the $Z$ transform of the correlation of each pixel with its eight neighboring pixels. Field size was calculated by measuring the number of contiguous pixels that clustered together. Only fields that contained nine or more contiguous pixels were included in these analyses.
Statistics. Statistical analysis was performed with SigmaStat (Aspire Software International) and Excel (Microsoft). Paired $t$ tests were used to compare freezing and correlation values obtained in the conditioning and neutral contexts in addition to rate change within fearconditioned animals. Independent $t$ tests were used to compare shortterm correlations, the degree of short-term remapping, correlations between $1 \mathrm{~h}$ and long-term sessions, correlations between 1 and $120 \mathrm{~h}$ in stable and remapping cells, average long-term correlations, and isolation distance between the experimental and control groups. For isolation distance, the $t$ test was computed over mean values for all sessions. Two-way ANOVAs with repeated measures and Tukey's post hoc tests were used to compare freezing behavior and speed between the fear-conditioned and control groups. A one-way ANOVA with repeated measures was used to compare behaviors (speed, avoidance, and elongation) during coyote odor exposure with other sessions within the fear-conditioned group.

The statistical analyses of average correlation values and other cell parameters (i.e., COM, firing rate, field size, and coherence) over time between fear-conditioned and control animals were conducted using linear mixed models (or multilevel models, see Verbeke and Molenberghs, 2000; McCulloch and Searle, 2001; Raudenbush and Bryk, 2002; Goldstein, 2010). Mixed models have been shown to be more effective than traditional linear models (e.g., ANOVA/multivariate ANOVA) for longitudinal studies with missing values or unbalanced conditions because they provide powerful and flexible algorithms that do not depend upon stringent assumptions such as sphericity and allow all of the available data to be used (Maxwell and Delaney, 2004). Because some cells were lost before the last retrieval test ( $120 \mathrm{~h}$ session), this analysis was the most appropriate.

A mixed-model approach is a fusion between Bayesian and frequentist inferences; both Bayesian and mixed-model approaches are hierarchical statistical models in which decisions about the data distribution are made a priori. However, in Bayesian approaches, all parameters must be specified, whereas in mixed models unknown parameters are estimated from the data, as in frequentist statistics (Goldstein, 2010). Here we use a mixed-model approach with a random slope model defined as follows:

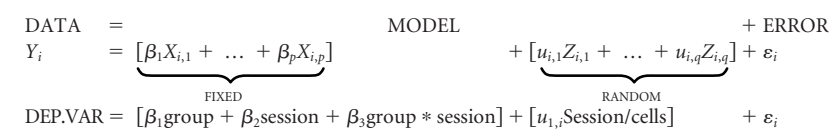

In this statistical approach, each dependent variable (DEP.VAR) can be approximated by the random slope model and the error $(\varepsilon)$, which represents what is not accounted for by the terms of the model. The random slope model includes two components: a fixed component [the addition of the $p$ independent variables or experimental treatments $(X)$ with their corresponding $\beta$ parameters, representing what each treatment explains about the variance of the dependent variables] and a random component [the addition of the $q$ variables $(Z)$ with their corresponding $u$ parameters, which measure variance in the experimental units (i) following changes in the independent variables, or treatments]. In our design, the fixed components $(p)$ consist of the three treatment effects: group (coyote or control), session (time of testing), and their interaction (group by session). These variable definitions coincide with that of classic linear models. The cells in our study were represented by the random component, which accounts for variations in the experimental units. Moreover, in longitudinal designs, mixed models estimate the variability of the experimental units more precisely by specifying an additional term, session (time of testing, modeled as a continuous variable). Thus, both terms would be nested (the Session/cells term in the equation shown above), allowing for the possibility that different cells display changes at varying rates; for example, some cells may display changes in stability faster than others. We conducted preliminary statistical analyses with this random slope equation, which we applied to all the dependent variables in our study. We also applied alternative mixed-model equations: a simpler one (random intercept model) and more complex ones with different error covariance structures (unstructured and first-order autoregressive models). We con- 
a

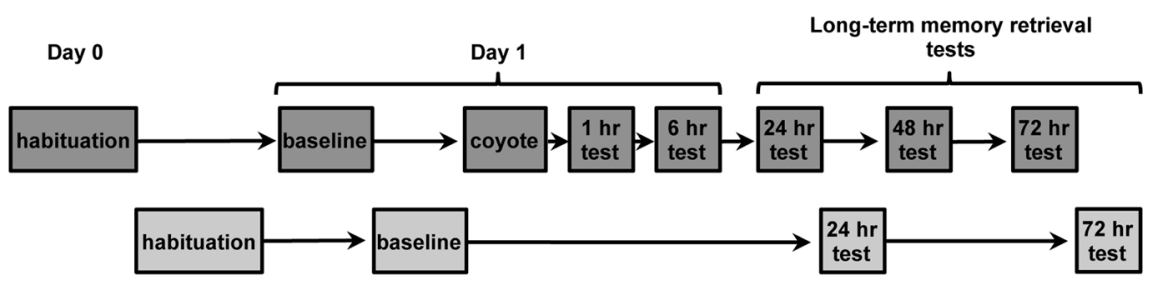

Control

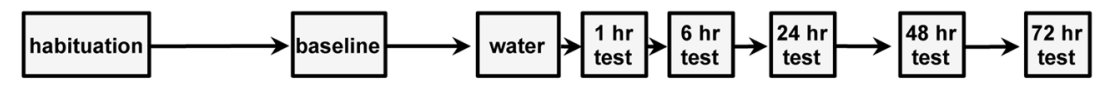

b

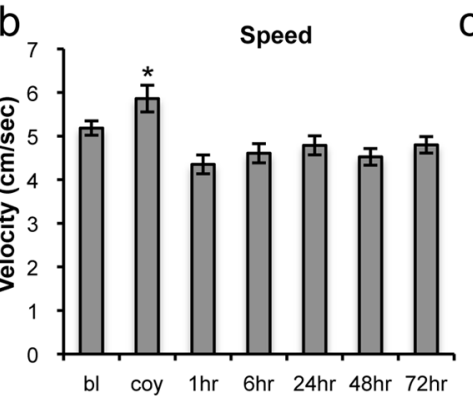

C

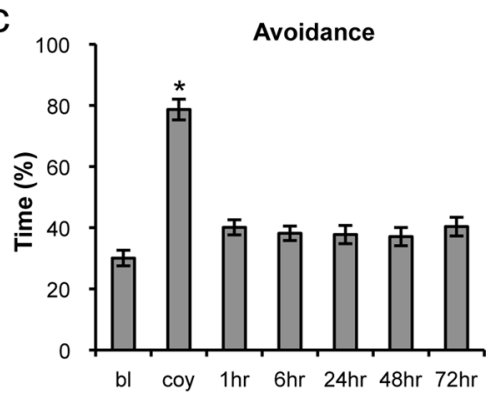

d

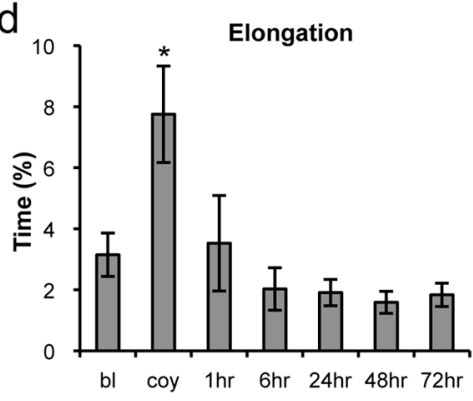

$\mathrm{e}$
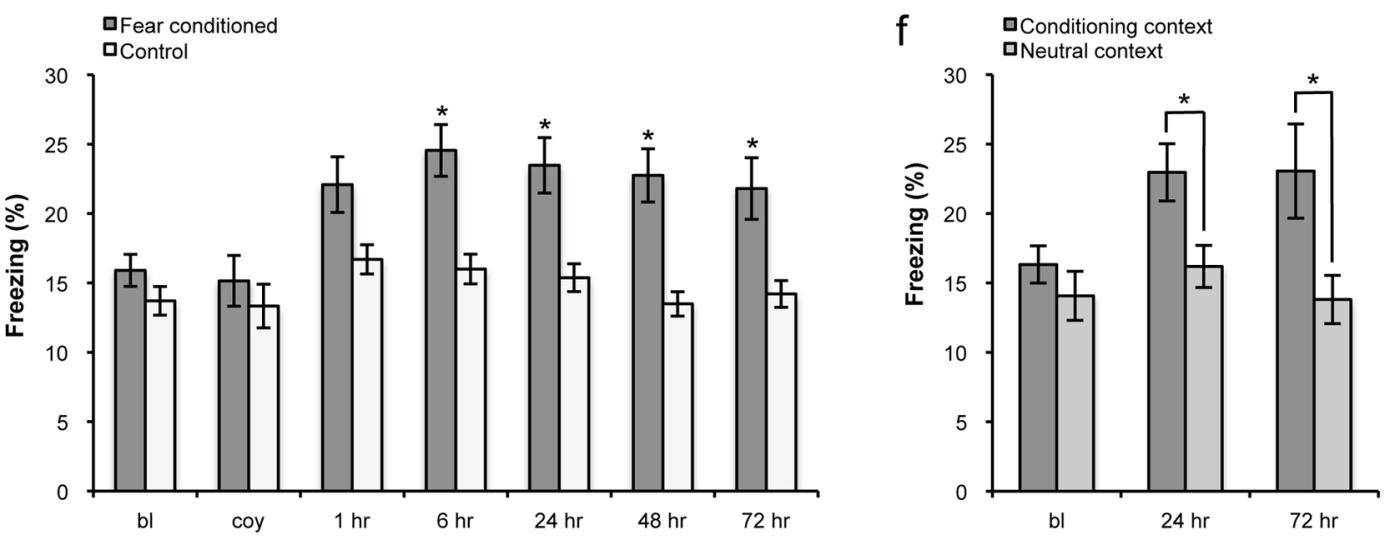

Figure 1. $\boldsymbol{a}$, A fear-conditioning protocol was designed with coyote urine as the US. The neutral context condition was run in a subset of fear-conditioned animals. $\boldsymbol{b}-\boldsymbol{d}$, Unconditioned responses to coyote odor in the fear-conditioned group comprising speed, avoidance, and elongation, respectively. $\boldsymbol{e}$, Fear-conditioned animals $(n=25)$ froze significantly more than control animals $(n=$ 21) exposed to water beginning at $6 \mathrm{~h}$ after coyote odor exposure. $\boldsymbol{f}$, Fear memory acquisition was specific to the training context, as fear-conditioned animals did not freeze in a similar neutral context. bl, Baseline; coy, coyote odor session. Means \pm SEM are shown in $\boldsymbol{b}-\boldsymbol{f}$. ${ }^{*} p<0.05$.

trasted the different alternative mixed-models using the Akaike information criterion test, concluding that the random slope model was the most efficient. The use of the random slope model involves the estimation of all the parameters ( $\beta$ and $u$ in the equation shown above) from the data with maximum-likelihood estimations. These estimations were then used to compute the probability values through conventional $t$ tests.

In all mixed-model analyses, we first tested group by session interactions. If there was a significant interaction, we tested for simple effects of group on each individual session using the multiple comparisons maxT type test statistic for mixed-model estimates (Maxwell and Delaney, 2004). If there was no significant interaction, we tested for main effects of group. If the group was significant, post hoc tests were not necessary since this variable had only two levels. All mixed-model analyses were performed using GNU R software (R Foundation for Statistical Computing) with nlme, lme4, and multcomp libraries (Faraway, 2006) and code written by M. M. Ramos Álvarez.

For all statistics, we used a significance level of 0.05. In all figures, an asterisk denotes a significant difference with a $p<0.05$, and error bars indicate \pm SEM. Error bars were adjusted in each session according to the number of cells included.

\section{Results}

\section{Predator odor fear conditioning}

To examine the role of the hippocampus in contextual fear memory, we first developed a novel contextual fear conditioning paradigm using a predator odor as the US. In the past, the success of such paradigms has been largely dependent on experimental conditions, and their efficacy has not been consistent (Rosen et al., 2008). Therefore, we tested the responses of C57BL/6 mice to a variety of predator odors and selected coyote urine as the most effective fearful stimulus (M. E. Wang, unpublished observations). To fear condition mice, we first habituated them to the training context $1 \mathrm{~d}$ before conditioning; this exposure enables the animal to form a representation of the context beneficial for contextual conditioning (Young et al., 1994). The following day, animals were placed in the same environment to take a baseline freezing measure and were then odor-exposed as described in Materials and Methods (Fig. 1a). As a control, we exposed a different group of mice to water rather than the predator odor, following the same schedule of context exposures. In both 
groups, fear was assessed in each session by calculating the cumulative percentage of time the animal spent freezing (maximum speed threshold, $0.6 \mathrm{~cm} / \mathrm{s}$ ) (Blanchard and Blanchard, 1969).

Unconditioned responses to predator odor We did not observe significant freezing during predator odor exposure, but rather an escape response characterized by an increase in average speed of movement (effect of session within the FC group: $F_{(6,96)}$ $=13.13, p<0.001$; Tukey's post hoc tests indicated significantly increased speed during coyote relative to all other sessions, $p<0.005$; Fig. $1 b)$. Additionally, we observed avoidance of the predator odor, as measured by increased time spent in the outer ring of the context furthest from the odor (effect of session within the FC group: $F_{(6,94)}=44.89, p<0.001$; Tukey's post hoc tests indicated significantly increased avoidance during coyote, $p<$ 0.001; Fig. 1c). Furthermore, animals tended to circle the outer perimeter and stretch into the center to investigate the predator odor. Since stretch-attend postures, marked by a flat-back position and increase in body length, are the most frequently used measures of defensive risk assessment behavior (Grant and Mackintosh, 1963; Dielenberg and McGregor, 2001), we measured body elongation and observed an increase during coyote odor exposure [effect of session within the FC group: $F_{(6,65)}=7.91, p<$ 0.001 ; Tukey's post hoc tests indicated significantly increased elongation during coyote $(p<0.001)$ compared with all other sessions except $1 \mathrm{~h}(p<0.095)$; Fig. $1 d]$. Together, these results demonstrate that, rather than freezing, mice exhibited other defensive behaviors in the presence of coyote odor. Moreover, since the unconditioned defensive responses to the odor were relatively mild, this paradigm allowed us to characterize spatial representations in the hippocampus during exposure to the fearful stimulus without interference from electrical noise (Oler et al., 2008), excessive freezing (Moita et al., 2004), or more aggressive unconditioned responses (e.g., jumping) produced by shock.

Interestingly, the expression of some defensive behaviors persisted in the short term even in the absence of the predator odor. While there was a slight increase in freezing at $1 \mathrm{~h}$, this increase was not significant. This was likely due to the intermixing of freezing with other fear responses that disappear when freezing reaches its maximal expression. For example, increased risk assessment indicated by body elongation remains moderately high during the $1 \mathrm{~h}$ session but returns to baseline levels beginning at $6 \mathrm{~h}$ after conditioning, coinciding with an increase in freezing (Fig. 1d). This negative correlation suggests that, in our paradigm, freezing is associated with the
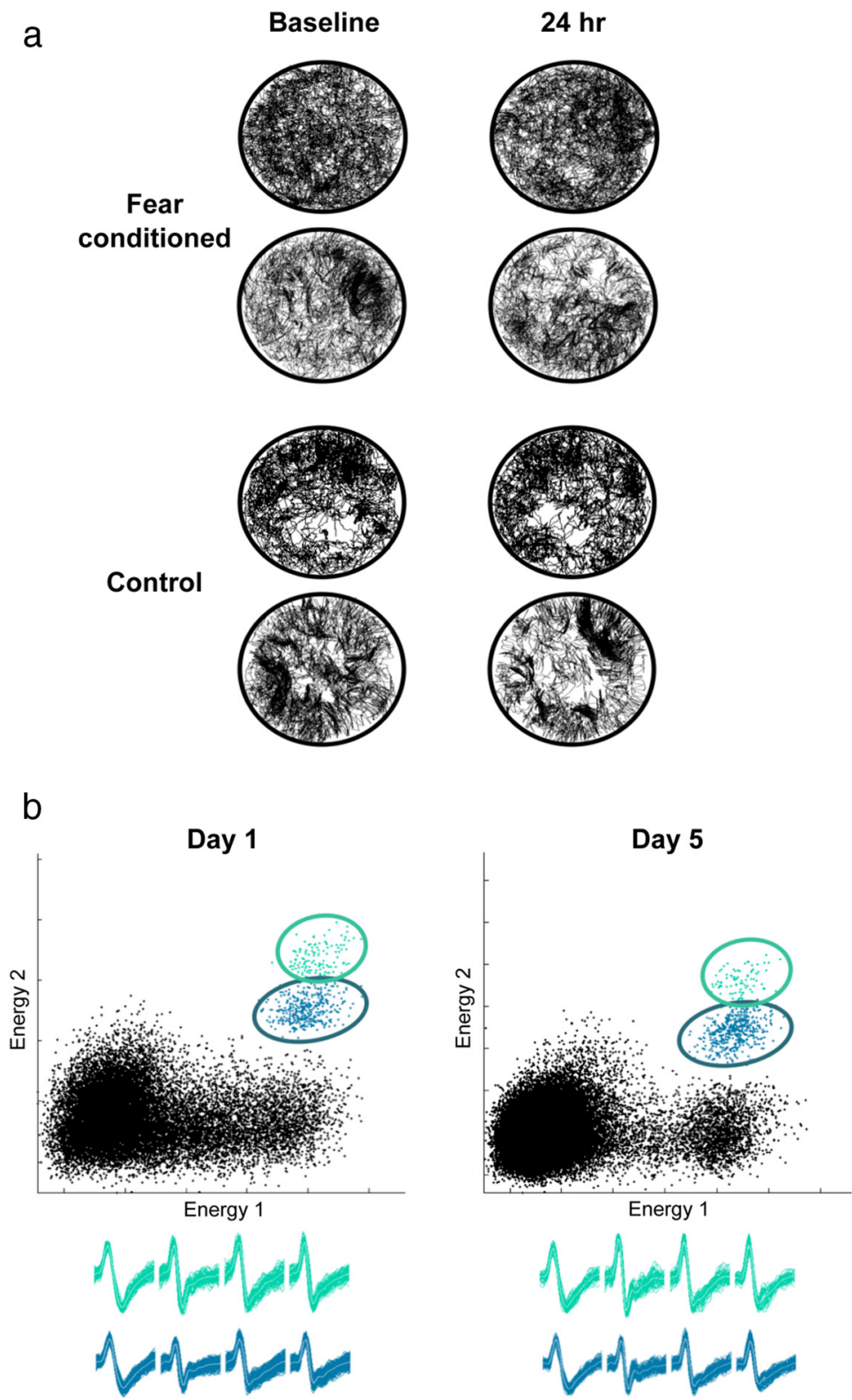

Figure 2. $\quad \boldsymbol{a}$, Fear conditioning does not affect sampling of the context. Representative examples of trajectories from two fear-conditioned (top panel) and two control (bottom panel) animals recorded in the training context before and after coyote odor exposure. Both animals sample all regions of the environment, which is essential for place cell recordings. The $24 \mathrm{~h}$ session is shown recording stability. The two cells shown were recorded for $5 \mathrm{~d}(120 \mathrm{~h})$ exhibiting minimal or no drift. Features used for cluster cutting included energy (i.e., sum of squared amplitude), peak amplitude, and time.

long-term expression of fear memory, whereas other behavioral measures may reflect a more immediate threat. From an evolutionary perspective, freezing is an effective fear response only if a predator is not in close proximity. However, in the presence of immediate danger, it is sometimes beneficial to switch to a flight response (Eilam, 2005). Our behavioral findings in the presence of predator odor, such as increased speed and avoidance, reflect these differential fear responses.

Long-term freezing in response to predator odor exposure

We found that one exposure to coyote odor produced significantly increased freezing during all memory retrieval tests after $6 \mathrm{~h}$ in the fear-conditioned group, whereas the control group did not exhibit increased freezing behavior (effect of group: $F_{(1,38)}=$ 
a Stable during predator odor exposure, remaps only at $1 \mathrm{hr}$

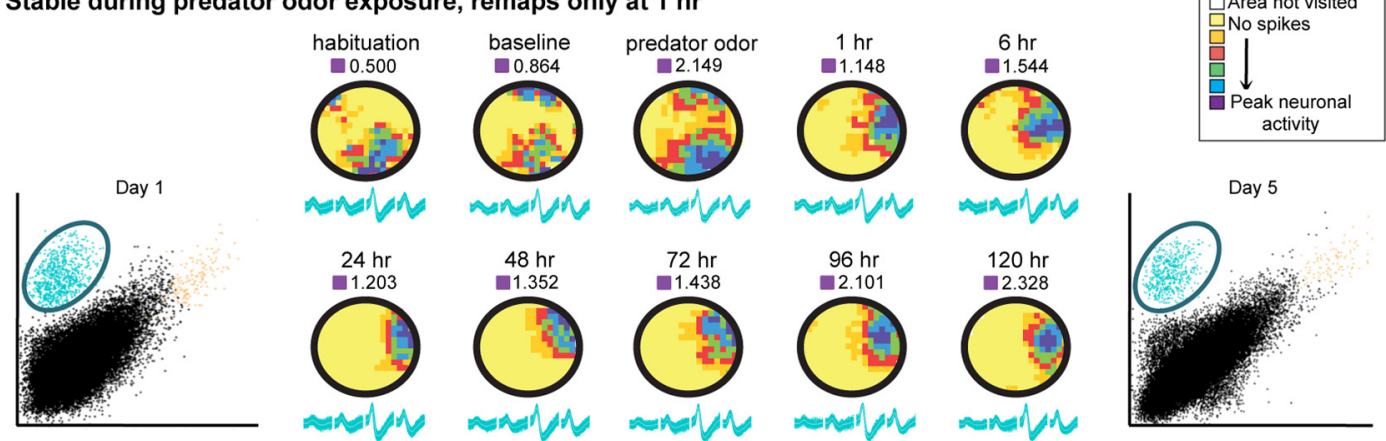

b Remaps during odor exposure, remaps again at $1 \mathrm{hr}$
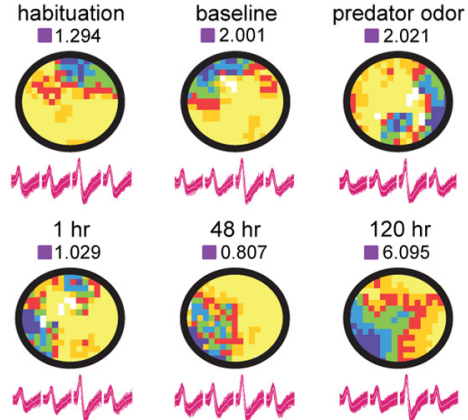

d

Stable during odor exposure, remains stable at $1 \mathrm{hr}$
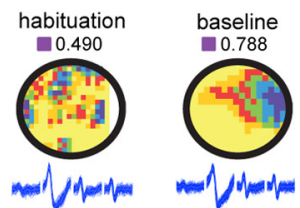

predator odor

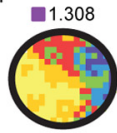

Ningom

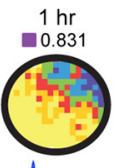

Ninering
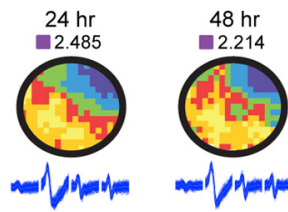

noming
C Remaps during odor exposure, remaps again at $1 \mathrm{hr}$
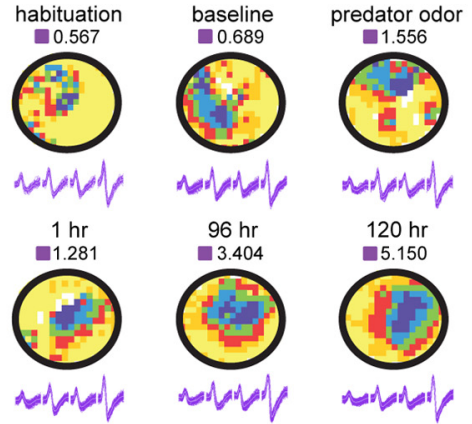

e Remaps during odor exposure, new map stabilizes at $1 \mathrm{hr}$
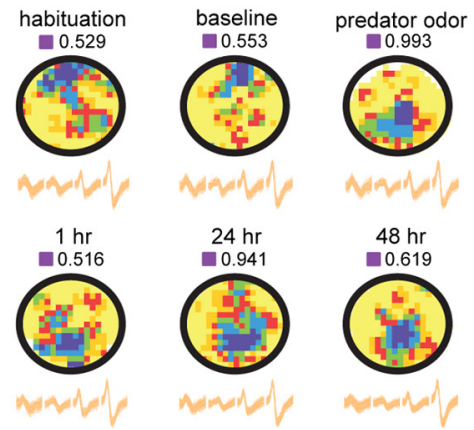

f Control cell: stable throughout short-term sessions, unstable in the long term

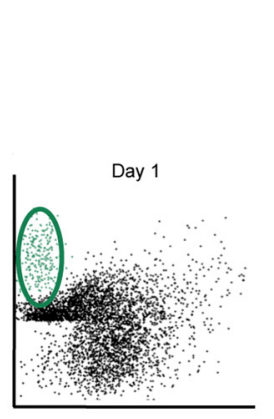

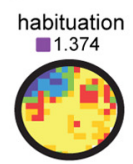
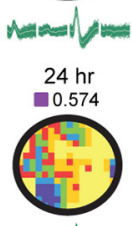

$n=1 / n=$

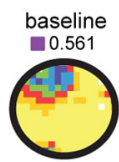

nacil $=$

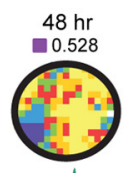

nataris
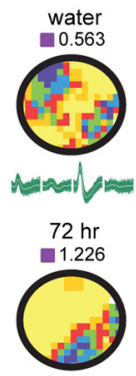

$x=1$
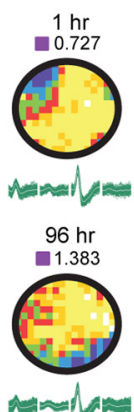
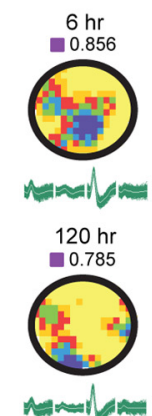

Day 5

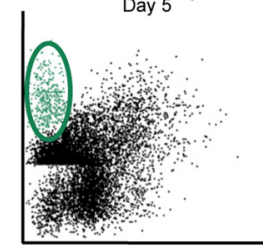

Figure 3. $\boldsymbol{a}-\boldsymbol{e}$, Examples of rate maps generated from cells recorded in fear-conditioned animals. In these maps, yellow indicates areas visited by the animal where the place cell does not fire, whereas increasingly vivid colors indicate higher firing frequencies. Cells exhibited heterogeneous responses during and shortly after fear conditioning: some were stable during predator odor exposure but remapped at $1 \mathrm{~h}(\boldsymbol{a})$, some remapped during coyote odor exposure and again at $1 \mathrm{~h}(\boldsymbol{b}, \boldsymbol{c})$, some remained stable throughout $(\boldsymbol{d})$, and some remapped in coyote but stabilized the new coyote map at $1 \mathrm{~h}(\boldsymbol{e})$. In all examples, cells became stable in the long term and the map that stabilizes is similar to the one formed directly after coyote odor exposure ( $1 \mathrm{~h}$ session). The blue cluster is the example cell shown in $\boldsymbol{a}$. $f$, Example of a rate map generated from a cell recorded in a control animal exposed to water. This place field is stable in the short term (baseline, water, and $1 \mathrm{~h}$ sessions) but unstable in the long term ( $24 \mathrm{~h}$ through $120 \mathrm{~h}$ ). The green cluster is the example cell shown in . Waveform and cluster constancy indicate stability in the recordings. Peak firing frequency for each session is indicated above each rate map.

5.757, $p<0.03$; effect of session: $F_{(6,251)}=7.869, p<0.001$; interaction: $F_{(6,251)}=2.796, p<0.02$; Tukey's post hoc tests indicated significantly increased freezing at 6, 24, 48, and $72 \mathrm{~h}, p<$ 0.05 ; Fig. 1e). These data suggest that the observed freezing was not due to a nonassociative process such as habituation. Additionally, the fear-conditioned animals exhibited contextspecific fear, since concurrent testing in a neutral context showed that freezing was elevated only in the conditioning 
context (24 h: $t_{(18)}=2.23, p<0.04$; 72 h: $t_{(13)}=3.08, p<0.005$; Fig. $\left.1 f\right)$. Together, these results indicate that our predator odor fear-conditioning paradigm is effective in producing long-term contextual fear memories. Importantly, this paradigm produced moderate but consistent levels of freezing. On average, animals in the fear-conditioned group did not spend $>25 \%$ of each retention test session freezing, compared with $\sim 15 \%$ freezing in the control group. Thus, the moderate long-term freezing levels elicited by predator odor conditioning permit full sampling of the context necessary for the analysis of place cell activity (Fig. 2a).

\section{Effects of fear on place cell activity}

To examine the effects of learned fear on place cell activity, we recorded from place cells in area CA1 of the dorsal hippocampus in vivo during predator odor contextual fear conditioning. For optimized recording stability, we implanted animals slightly above the hippocampus and moved the electrodes slowly over several weeks to minimize inflammatory responses (Kentros et al., 2004; Muzzio et al., 2009b). Once hippocampal cells were identified by their characteristic firing patterns (Ranck, 1973), we assessed recording stability by examining waveform and cluster constancy (Figs. 2b, 3a,d). Isolation distance was calculated to provide a measure of cluster quality (see Materials and Methods), and cells in both groups displayed similar values $\left(t_{(47)}=-0.39\right.$; $p=0.34)$. We then generated place cell rate maps and compared the maps of each recording session with that of the subsequent session, calculating correlations between sessions on a pixel-by-pixel basis for each cell. Only periods of movement during which the minimum walking speed was $3 \mathrm{~cm} / \mathrm{s}$ were included in the place field analysis. Importantly, when periods of freezing were excluded, there was no difference in average speed between the fear-conditioned and control animals in any of the $10 \mathrm{~min}$ sessions (effect of group: $\left.F_{(1,5)}=0.535, p=0.46\right)$.

\section{Short-term effects of fear on place} cell activity

To determine the short-term effects of fear on place cell activity, we analyzed 48 cells from seven fear-conditioned animals and 20 cells from three control animals (Table 1). The control group exhibited high short-term stability, indicated by high correlations between place fields, as has been previously shown (Kentros et al., 2004; Muzzio et al., 2009b). However, the
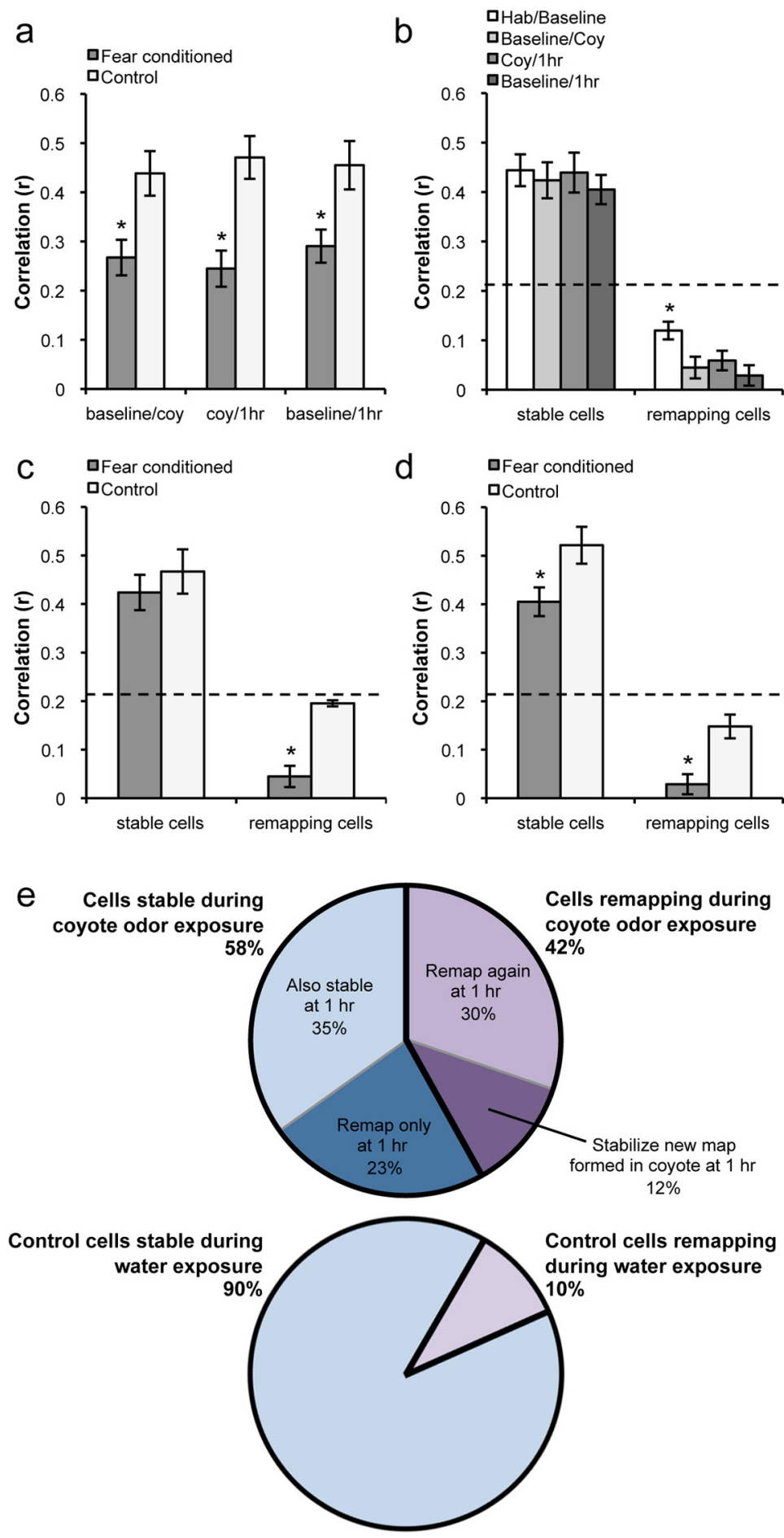

Figure 4. $\quad \boldsymbol{a}$, Comparison of average correlations between groups during short-term sessions. The fear-conditioned group shows significantly lower short-term correlations due to remapping in a subset of cells. $\boldsymbol{b}$, Within fear-conditioned animals, short-term remapping induced by fear was more robust than long-term remapping between habituation and baseline. $\boldsymbol{c}, \boldsymbol{d}$, Between-group comparisons of stable and remapping cells between baseline and coyote odor exposure (c) and baseline and $1 \mathrm{~h}$ (d). Unstable cells in the fear-conditioned group remapped significantly more than the few unstable cells in the control group in both sessions. Furthermore, stable cells were also significantly less stable in the fear-conditioned group when comparing the baseline and $1 \mathrm{~h}$ sessions (d). e, Top, Pie chart showing percentage of stable (58\%) and remapping (42\%) cells during coyote odor exposure. Within these two groups, cells are further subdivided into their responses $1 \mathrm{~h}$ after conditioning. Bottom, Pie chart showing percentage of stable ( $90 \%$ ) and remapping (10\%) cells during the conditioning session of the control group. There are no further subdivisions of cells in the control group because no remapping is observed between the conditioning session and the $1 \mathrm{~h}$ session. The dotted lines indicate stability threshold $(r=0.21)$. Means \pm SEM are shown. ${ }^{*} p<0.05$. 


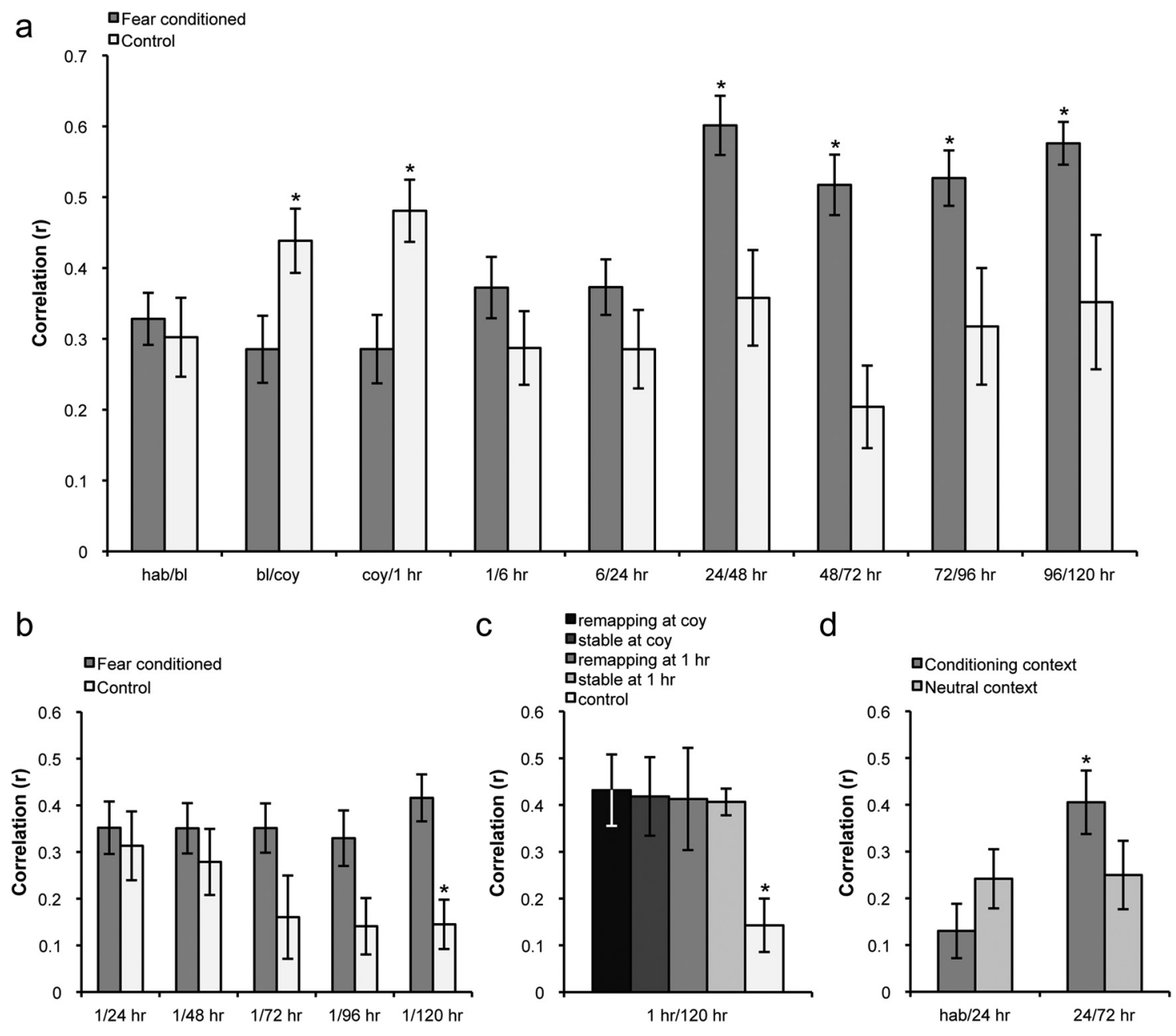

Figure 5. a, Average place field correlations indicating stability over time. The control group exhibited high short-term stability, while the fear-conditioned group exhibited remapping during both the conditioning and $1 \mathrm{~h}$ sessions. In the long term, only cells in the fear-conditioned group displayed increases in stability beginning at $24 \mathrm{~h}$ postconditioning. $\boldsymbol{b}$, Average place field correlations between the $1 \mathrm{~h}$ session and each long-term test session. The maps stabilizing in the long term resembled those formed after predator odor exposure, as evidenced by continually high correlations between the $1 \mathrm{~h}$ session and each of the long-term sessions. Conversely, control animals exhibited a steady long-term decrease in stability in corresponding sessions. $c$, All cells tended to form maps in the long term that resembled the $1 \mathrm{~h}$ session regardless of whether they showed short-term remapping or stability, and were significantly different from the average correlation between 1 and $120 \mathrm{~h}$ of all cells in the control group. Histogram shows average correlations between 1 and $120 \mathrm{~h}$ sessions. $\boldsymbol{d}$, Place field stability in the training context compared with a neutral context in fear-conditioned animals. Between 24 and $72 \mathrm{~h}$, there was an increase in stability that was specific to the training context. hab, Habituation; bl, baseline; coy, coyote. Means \pm SEM are shown. ${ }^{*} p<0.05$.

fear-conditioned group exhibited significantly decreased stability during both the conditioning and $1 \mathrm{~h}$ test sessions compared with the control group $\left(t_{(63)}=-2.73, p<0.009\right.$, and $t_{(56)}=-3.4, p<0.002$, respectively; Figs. 3, 4a). A remapping index $(r=0.21)$ was obtained by calculating the average stability between two contexts with different visual cues (see Materials and Methods). Cells exhibiting correlation values of 0.21 or below between a session and its preceding session were considered unstable, or remapping, and cells with correlation values $>0.21$ were considered stable. We found that $42 \%$ of place cells remapped, displaying a shift in place field firing location during coyote odor exposure, compared with $10 \%$ of cells in control animals not exposed to the predator odor. Interestingly, when animals were reintroduced to the context shortly after the odor exposure ( $1 \mathrm{~h}$ session), 53\% of cells in the experimental group displayed remapping compared with the coyote odor session, while no unstable cells were observed in the control group. Although there does not appear to be an overall difference between the baseline long-term correlation scores and those reported during the coyote odor and $1 \mathrm{~h}$ sessions (Fig. $5 a$ ), it is important to note that, in contrast to the long-term place field instability usually observed in mice in the absence of a task contingency (Kentros et al., 2004; Muzzio et al., 2009b), remapping in this case occurs during consecutive short-term sessions, which are typically very stable as observed in the control group. During these trials, we also looked for cells disappearing and new cells appearing in response to coyote odor exposure, but did not find evidence of this sort of remapping.

We performed additional analyses to more closely investigate the remapping phenomenon observed during and shortly after fear conditioning. One possibility is that the instability observed after the coyote odor session is due to the cells reverting to their preferred firing location before coyote odor exposure. If this were the case, a high correlation between the $1 \mathrm{~h}$ and baseline sessions would be expected. Alternatively, if the animals' perception of the environment changes after conditioning, the cells would likely display further remapping at $1 \mathrm{~h}$. In this case, we would anticipate a low correlation between the baseline and $1 \mathrm{~h}$ sessions. To address these possibilities, we calculated the correlation between the $1 \mathrm{~h}$ and baseline sessions. We found that this average correlation 
was relatively low in the conditioned animals, similar to those observed when comparing baseline to coyote odor exposure and odor exposure to $1 \mathrm{~h}$ (Fig. $4 a$ ). Moreover, this correlation value was significantly different from the high stability observed in control cells (baseline vs $1 \mathrm{~h}$ sessions between groups: $t_{(59)}=$ $-2.55, p<0.014)$. These results suggest that animals perceive the context as different after predator odor exposure.

To further characterize the short-term remapping observed after conditioning, we examined how cells responded during the $1 \mathrm{~h}$ session based on their stability during coyote odor exposure (Fig. 4 ). We found that $23 \%$ of all cells were stable during the coyote odor exposure and remapped only in the $1 \mathrm{~h}$ session (Fig. $3 a$ ), suggesting that some cells selectively respond to the learned emotional valence of the context rather than to the odor itself. The $42 \%$ of cells that remapped during coyote odor exposure (unstable cells) was composed of $30 \%$ that remapped further at $1 \mathrm{~h}$ (Fig. 3b,c) and 12\% that stabilized the fields formed during the coyote odor session (Fig. $3 e$ ). Additionally, we found that $35 \%$ of all cells did not respond to predator odor exposure at all, remaining stable throughout odor exposure and $1 \mathrm{~h}$ later (Fig. $3 d$ ).

To quantify the degree of remapping observed in response to conditioning described above, we used the remapping index (0.21) to divide the recorded cells into two subpopulations for each session: unstable and stable. First, we examined these subpopulations within the fear-conditioned group to determine whether there were differences in stability before and after conditioning. We compared these subpopulations between habituation and baseline, baseline and coyote odor exposure, coyote odor exposure and $1 \mathrm{~h}$, and baseline and $1 \mathrm{~h}$ sessions (Fig. 4b). We found that, while fear conditioning had no effect on stable cells, the subpopulation of unstable cells displayed significantly lower correlations during and after conditioning than in baseline sessions (hab/bl vs bl/coy: $t_{(32)}=$ 2.62, $p<0.014$; hab/bl vs coy/ 1 h: $t_{(35)}=2.18, p<0.04$; hab/bl vs $\left.\mathrm{bl} / 1 \mathrm{~h}: t_{(27)}=3.45, p<0.003\right)$. These results indicate that, among unstable cells, the remapping observed in response to fear conditioning is more robust than baseline remapping. Importantly, this robust remapping occurred in consecutive recording sessions, whereas the more moderate baseline remapping occurred in sessions recorded $18-20 \mathrm{~h}$ apart. Since long-term representations recorded in mice are typically characterized by relatively low stability in contrast to high short-term stability, the pronounced remapping observed in unstable cells as a consequence of conditioning is particularly meaningful.

We then compared stable and unstable cells between groups in the same sessions to determine whether the degree of remapping in unstable cells was different between the conditioned and control groups. We found that correlations of unstable cells during and shortly after the conditioning session were significantly lower than those in the control group during the same time points (comparisons between conditioned and control groups: baseline-coyote: $t_{(19)}=-2.24, p<0.04$; and baseline $-1 \mathrm{~h}: t_{(15)}=-2.64, p<0.02 ;$ Fig. $\left.4 c, d\right)$. In fact, the few unstable cells in the control group displayed correlation values only slightly below the remapping index (0.21). These analyses indicate that, among unstable cells, there is significantly more remapping in the conditioned animals than in control animals during the same sessions. Furthermore, the stable cells in the conditioned group also displayed lower correlations than those in the control group when comparing the $1 \mathrm{~h}$ and baseline sessions $\left(t_{(43)}=3.25, p<0.03\right.$; Fig. $\left.4 d\right)$, suggesting that the overall stability of short-term representations was affected by condi-
Table 2. Firing properties of hippocampal place cells, including COM shift and coherence

\begin{tabular}{lcr}
\hline Session & Fear conditioned & Control \\
\hline $\begin{array}{l}\text { Center of mass shift }(\mathrm{cm}) \\
\text { hab/bl }\end{array}$ & & \\
$\mathrm{bl} / \mathrm{coy}$ & $8.6 \pm 1.1$ & $8.4 \pm 1.1$ \\
coy/1 h & $12.5 \pm 1.5^{*}$ & $4.3 \pm 0.4$ \\
$1 / 6 \mathrm{~h}$ & $9.3 \pm 1.2^{*}$ & $4.7 \pm 1.6$ \\
$6 / 24 \mathrm{~h}$ & $8.4 \pm 1.1$ & $7.8 \pm 1.3$ \\
$24 / 48 \mathrm{~h}$ & $8.9 \pm 1.2$ & $6.6 \pm 1.1$ \\
$48 / 72 \mathrm{~h}$ & $5.9 \pm 1.5$ & $4.8 \pm 1.5$ \\
$72 / 96 \mathrm{~h}$ & $7.1 \pm 0.8$ & $12.4 \pm 1.2^{*}$ \\
$96 / 120 \mathrm{~h}$ & $7.7 \pm 1.1$ & $11.3 \pm 2.6^{\dagger}$ \\
Coherence & $5.8 \pm 1.0$ & $10.8 \pm 3.0^{*}$ \\
hab & & \\
$\mathrm{bl}$ & $0.16 \pm 0.03$ & $0.13 \pm 0.02$ \\
coy & $0.17 \pm 0.03$ & $0.14 \pm 0.03$ \\
$1 \mathrm{~h}$ & $0.15 \pm 0.02$ & $0.11 \pm 0.03$ \\
$6 \mathrm{~h}$ & $0.22 \pm 0.03^{*}$ & $0.11 \pm 0.04$ \\
$24 \mathrm{~h}$ & $0.13 \pm 0.02^{\dagger}$ & $0.2 \pm 0.04$ \\
$48 \mathrm{~h}$ & $0.27 \pm 0.03$ & $0.19 \pm 0.05$ \\
$72 \mathrm{~h}$ & $0.22 \pm 0.03$ & $0.17 \pm 0.05$ \\
$96 \mathrm{~h}$ & $0.22 \pm 0.02^{\dagger}$ & $0.15 \pm 0.03$ \\
$120 \mathrm{~h}$ & $0.22 \pm 0.03^{*}$ & $0.1 \pm 0.05$ \\
\hline
\end{tabular}

Means \pm SEM are shown.

${ }^{*} p<0.05$.

${ }^{\dagger} p<0.14$.

tioning. Together, these findings suggest that, during and shortly after US exposure, cells in the fear-conditioned group display a significant degree of remapping.

We also analyzed shifts in the COM, an additional measure of stability that evaluates displacement in the center of the place field between sessions. We found that COM shifts corresponded with our previous remapping analyses and increased significantly during and directly after fear conditioning, reflecting the lower correlations observed in a subset of cells (effect of session: $F_{(8,215)}=2.222, p<0.027$; interaction: $F_{(8,215)}=5.514, p<$ 0.0001 ; post hoc analysis indicated that groups were significantly different during coyote, $p<0.0001$, and $1 \mathrm{~h}, p<0.026$; Table 2 ). Although it appears that the enhanced COM shifts observed during the coyote and $1 \mathrm{~h}$ sessions relative to baseline are more robust than the changes observed in the correlation analysis relative to baseline, it is important to note that COM shifts are a correlated but different measure of stability. Thus, although the two analyses do not produce precisely the same results, they are not inconsistent. These results illustrate that hippocampal neurons display a variety of cellular changes in response to coyote odor exposure.

In addition to partial remapping, we found that $92.3 \%$ of the cells recorded during coyote odor exposure displayed an increase in firing rate. On average, the in-field firing rate doubled during the coyote odor session compared with the baseline session and was observed in cells that were stable as well as those that remapped (effect of group: $F_{(1,50)}=8.325, p<0.006$; session: $F_{(9,298)}=5.532, p<0.0001$; interaction: $F_{(9,298)}=2.484, p<$ 0.01 ; multiple comparisons indicated significantly increased infield firing rates during coyote, $p<0.0001$; and $1 \mathrm{~h}, p<0.015$; Fig. $6 a$ ). We quantified rate change between sessions in the fearconditioned group by calculating a rate difference of the in-field firing rate for each cell ([session - previous session]/[sum]). During coyote odor exposure, this rate change was significantly higher than the baseline change in firing rate $\left(t_{(27)}=-2.55, p<\right.$ 0.017; Fig. $6 b$ ). At $1 \mathrm{~h}$ after conditioning, the change in firing rate 

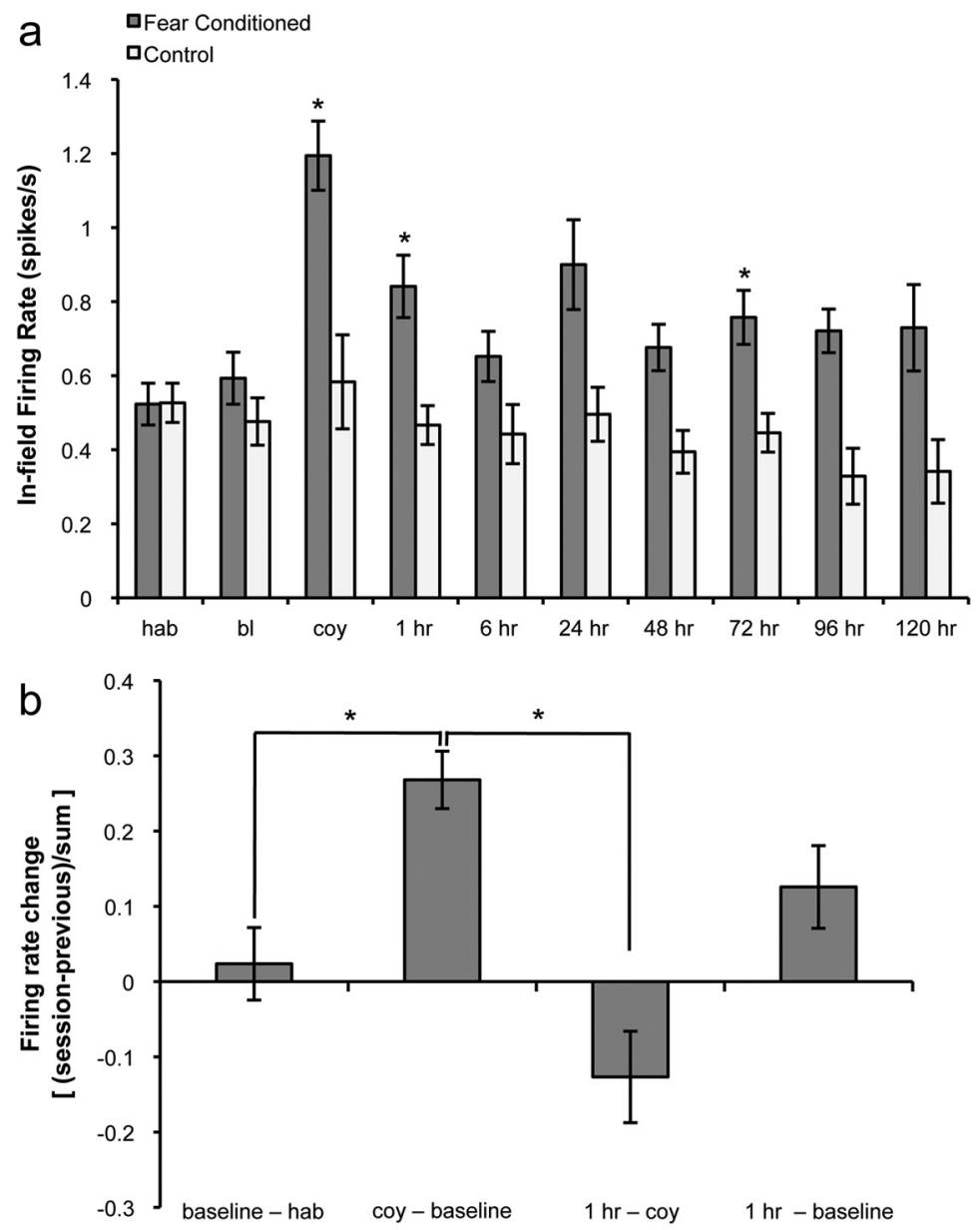

Figure 6. Fear conditioning affects in-field firing rate. $\boldsymbol{a}$, Histograms showing average in-field firing rate. Fear-conditioned animals displayed significantly higher in-field firing rates during coyote odor, $1 \mathrm{~h}$, and $72 \mathrm{~h}$ sessions, with a trend toward significance at other long-term tests $(24,48,96 \mathrm{~h}) . \boldsymbol{b}$, Firing rate changes during the coyote odor and $1 \mathrm{~h}$ sessions in the conditioned group. The firing rate change was determined for each cell using the following formula: [session - previous session]/[sum]. The rate change between habituation and baseline sessions was close to zero. During coyote odor exposure, this rate change was significantly higher than the baseline change in firing rate. At $1 \mathrm{~h}$ after conditioning, the change in firing rate decreased significantly from the coyote odor session but remained high compared with the baseline session, although this effect did not reach statistical significance $(p=0.058)$. hab, Habituation; bl, baseline; coy, coyote. Means \pm SEM are shown. ${ }^{*} p<0.05$.

decreased significantly from the coyote odor session $\left(t_{(24)}=4.35\right.$; $p<0.001)$. Additionally, there appeared to be an increase in firing rate change at $1 \mathrm{~h}$ from the baseline session compared with the baseline rate change, although this trend did not reach significance $(p=0.058)$. These changes in firing rate observed in the conditioned group are a further indication that the presence of a predator odor significantly alters the hippocampal representation of a context. Together, our findings indicate that exposure to a fearful stimulus changes an animal's perception of a context, resulting in the formation of a novel hippocampal representation of the environment.

Long-term effects of fear on place cell activity

We continued recording from the same neurons for up to $5 \mathrm{~d}$ $(120 \mathrm{~h})$ after fear conditioning to determine the long-term effects of fear on place cell activity. We found significantly increased stability between all consecutive long-term memory retrieval test sessions beginning at $24 \mathrm{~h}$ postconditioning (effect of session: $F_{(8,291)}=4.347, p<0.0001$; interaction: $F_{(8,291)}$ $=5.599, p<0.0001$, post hoc analysis indicated that groups were significantly different at 24/48 h, 48/72 h, 72/96 h, and 96/120 h, $p<0.05$; Fig. 5a). Moreover, conditioning decreased COM shifts between sessions in the long term, an additional indicator of long-term stability (effect of session: $F_{(8,215)}=2.222, p<$ 0.027; interaction: $F_{(8,215)}=5.514, p<$ 0.0001 ; groups significantly different at $72 \mathrm{~h}, p<0.0001$; and $120 \mathrm{~h}, p<0.043$; there was also a trend toward significance at $96 \mathrm{~h}, p=0.145$; Table 2). Interestingly, many of the maps stabilizing in the long term tended to resemble those formed directly after predator odor exposure, as evidenced by relatively high correlations between the $1 \mathrm{~h}$ and long-term sessions compared with the control group in corresponding sessions (Fig. 5b). The control animals exhibited a steady long-term decrease in place field similarity, with significantly less stability between the 1 and 120 h sessions $\left(t_{(26)}=3.077, p<0.006\right.$; trends at $1 \mathrm{~h} / 96 \mathrm{~h}, p=0.072$; and $1 \mathrm{~h} / 72 \mathrm{~h}$, $p=0.075)$. Upon further analysis, $90 \%$ of cells in the fear-conditioned group were stable between the 1 and $120 \mathrm{~h}$ sessions, compared with $37.5 \%$ in control animals. This long-term stability was apparent regardless of whether the cell remapped or remained stable during the coyote odor and $1 \mathrm{~h}$ sessions, and was significantly different from the control group $(p<0.05$; Fig. $5 c$ ). Therefore, our data indicate that the representations occurring shortly after fear conditioning stabilize in the long term.

To corroborate the place field stabilization observed after conditioning, we also examined the long-term effects of fear conditioning on firing rate. Conditioning increased in-field firing rates at various long-term retrieval sessions (effect of group: $F_{(1,50)}=8.325, p<0.006$; effect of session: $F_{(9,298)}=5.532, p<$ 0.0001; interaction: $F_{(9,298)}=2.484, p<$ 0.01; Fig. 6a). Post hoc multiple comparisons indicated that firing rates were significantly different at $72 \mathrm{~h}(p<0.047)$ with a trend toward significance at other long-term tests $(24 \mathrm{~h}, p=0.075$; $48 \mathrm{~h}, p=0.108 ; 96 \mathrm{~h}, p=0.110)$. These data suggest a long-lasting effect of fear conditioning on place cell firing rates. Importantly, $40 \%$ of all cells from the fear-conditioned group did not display long-term increases in firing rate relative to preconditioning sessions. We calculated average long-term stability for these cells by taking the mean of correlations between all long-term sessions (from $6 \mathrm{~h} / 24 \mathrm{~h}$ to $96 \mathrm{~h} / 120 \mathrm{~h}$ ) for each cell, and compared these values with those of the control group. We found that stability was significantly higher in fear-conditioned animals even when excluding cells exhibiting increased long-term firing rates $\left(t_{(29)}=\right.$ 2.76; $p<0.01)$. These data confirm that the increase in place cell stability observed after fear conditioning occurs independently of changes in firing rate. Furthermore, the increases in place field stability and firing rates occurred without differences in field size between groups $(p>0.05)$, indicating that the observed changes are not a result of place field expansion.

It is of interest to note that our firing rates are slightly lower than those previously reported in mice. This may be accounted 
for by the size of our training context, as place cell firing rates are partially a function of speed. Our smaller context, which allowed animals to move freely but prevented long bouts of high-speed running, was necessary to obtain contextual conditioning using a predator odor (see Materials and Methods). As a result, the average speed of movement in this study was $4.7 \mathrm{~cm} / \mathrm{s}$, which is lower than the average speeds observed when mice were placed in larger contexts (Kentros et al., 2004; Muzzio et al., 2009b). However, our firing rates are comparable with previously reported values obtained when mice were placed in a context of a similar size (McHugh et al., 2007). Furthermore, since both the control and fear-conditioned groups displayed similar average speeds, the resulting lower average firing rates observed in both groups do not affect the significance of our findings.

To determine the specificity of the stabilization effect, we recorded from two fear-conditioned animals in a neutral context concurrent with training. The long-term increase in place cell stability observed in the fear-conditioned group was specific to the training context and was not observed in the neutral context (interaction: $F_{(1,32)}=5.75, p<0.03$, post hoc analysis indicated that contexts were significantly different in $24 / 72$ h comparison, $p<0.05$; Fig. $5 d$ ). Our results indicate that animals discriminate the conditioning context on both the behavioral and physiological levels. Additionally, we observed an increase in coherence of place fields after conditioning, indicative of enhanced field organization (effect of session: $F_{(9,351)}=1.933, p<0.047$; interaction: $F_{(9,351)}=$ 2.117, $p<0.028$; post hoc tests indicated significantly higher coherence in FC group at $1 \mathrm{~h}, p<0.043$; and $96 \mathrm{~h}, p<0.037$; with a trend toward significance at $72 \mathrm{~h}, p=0.107$; and $120 \mathrm{~h}$, $p=0.066$; Table 2). It is important to note that, on average, our coherence values are moderate because they are dependent upon the amount of time an animal spends in an environment. To study fear conditioning, it was essential to find a balance between proper sampling and preventing extinction, which required recording relatively short sessions. Finally, we correlated average long-term freezing with average long-term place field stability in fear-conditioned animals. While there was a moderate positive correlation between freezing and place cell stability $(r=0.33)$, this was not statistically significant $(p>0.05)$. Together, these data suggest that a novel spatial representation of a fearful context is formed in the hippocampus directly after a fearful event, and this representation persists in the long term.

\section{Discussion}

We have demonstrated that the hippocampus contributes to contextual fear memory formation by creating a distinct, stable spatial representation of the location in which a fearful event occurs. This was evidenced by increased long-term place field stability and enhanced firing rates observed in animals conditioned to the predator odor; these effects were not seen in animals exposed only to water. Importantly, the stabilized spatial representations resemble those formed shortly after predator odor exposure. These results suggest that the spatial map formed immediately after a fearful event can persist over a sustained period of time, paralleling the long-lasting nature of emotional memories. While it is possible that other processes, such as increased arousal or attention to the context, may contribute to the observed longterm stability, these processes are potential corollaries of fear conditioning and do not preclude contextual fear learning as the likely cause of place cell stabilization.
This is the first study in which place cell activity has been successfully recorded during the presentation of a US. Interestingly, we found that the US used in this study produced only partial remapping, a phenomenon that has been previously described in place cell populations (Quirk et al., 1990; Tanila et al., 1997; Knierim, 2002; Anderson and Jeffery, 2003). Since place cells can be influenced by both spatial and nonspatial cues such as task contingencies (for review, see Muzzio et al., 2009a) and odors placed in varying locations (Wood et al., 1999; Muzzio et al., 2009b), it is likely that the cells remaining stable during coyote odor exposure primarily encode visuospatial information, while the remapping cells are sensitive to other contextual cues such as odor or emotional valence. Additionally, our findings support the view that partial remapping is a product of various reference frames modulating the activity of different sets of hippocampal cells (Colgin et al., 2008). Several place cell studies have shown that reference frames can be fixed to visuospatial landmarks, behavioral states, or task-relevant information, demonstrating the coexistence of multiple representations of a single environment (Wiener et al., 1989; Markus et al., 1995; Gothard et al., 1996; Zinyuk et al., 2000; Ferbinteanu and Shapiro, 2003). Thus, the partial remapping we observed may be produced by two different reference frames: one associated with spatial cues and the other with emotional valence.

The remapping observed shortly after predator odor exposure is consistent with a previous finding that place cells remap $1 \mathrm{~h}$ after contextual conditioning with electric shock (Moita et al., 2004). This remapping is of particular interest because the presence of the odor itself is a possible source of remapping during conditioning. As the predator odor is not physically present during the $1 \mathrm{~h}$ trial, it is likely that the novel representations formed shortly after coyote odor exposure are a direct response to new emotional significance ascribed to the context. It then follows that the representations occurring $1 \mathrm{~h}$ after fear conditioning stabilize in the long term, because the same negative emotional valence of the context is present during the long-term memory retrieval tests while the odor is not. From a molecular standpoint, the hippocampal representations formed $1 \mathrm{~h}$ after fear conditioning may be consolidated because it is the animals' final exposure to the fearful environment before protein synthesis and longterm memory consolidation (Bourtchouladze et al., 1998). Memories are dynamic and susceptible to changes over time, particularly when a memory is initially encoded. During this period, the memory trace is labile and can be modified (McGaugh, 1966). Therefore, the instability observed in the short term could be a result of the labile nature of short-term memories correlating with the experience of fear learning; however, once a memory is consolidated, its representation may become stable over time. In accordance with this idea, we found significantly increased stability beginning at $24 \mathrm{~h}$ postconditioning. This is consistent with previous findings that implicate the hippocampus specifically in long-term contextual memory: hippocampal lesions impair contextual fear memory $24 \mathrm{~h}$ but not immediately after fear conditioning (Kim et al., 1993), and long-term memory storage in this region requires late protein synthesis $12 \mathrm{~h}$ after acquisition (Bekinschtein et al., 2007).

Previous studies have indicated that firing rates can be affected by changes in nonspatial sensory inputs, which are primarily relayed to the hippocampus through the lateral entorhinal cortex (Deshmukh and Knierim, 2011). Accordingly, changes in place cell firing rates have been observed in response to a previously fear-conditioned tone played while an animal passes through the firing field of a particular cell (Moita et al., 2003). Since nonspa- 
tial task-relevant stimuli have also been shown to modify firing rates (Muzzio et al., 2009b), the robust increase in firing rate observed during presentation of the US is potentially a result of the change in sensory salience of the context created by introducing the predator odor. Furthermore, the maintenance of moderately elevated firing rates after conditioning suggests that the animal continues perceiving the context as salient in the long term.

An intriguing question concerns the necessity of consolidating contextual representations in the hippocampus. Several lines of evidence indicate that, while the hippocampus is required for the formation and initial consolidation of new memories, this region becomes less critical as time passes (Frankland and Bontempi, 2005). Thus, hippocampus-dependent memory consolidation has been classically divided into two processes: cellular and systems consolidation. The molecular and physiological events occurring during cellular consolidation are engaged to enhance local circuitry involved in memory consolidation. This is generally thought of as a fast process, operating over a period of hours to days, and these synaptic events occur in the hippocampus where multimodal stimuli, both internal and external, are integrated within a spatial framework. As a memory ages, it becomes less dependent on the hippocampus and is presumed to be transferred to cortical areas for permanent storage, a process termed systems consolidation (Dudai, 2004). This idea raises the question of why it might be necessary to consolidate a spatial representation in the hippocampus at the physiological level. While some studies suggest that long-term memories can be retrieved without hippocampal involvement (Squire and Wixted, 2011), others indicate that the hippocampus is required for the retrieval of detailed long-term episodic memories and even semantic memories including spatial information (Hoscheidt et al., 2010). Moreover, it has been shown that brief inhibition of hippocampal cells in area CA1 blocks retrieval of a remote contextual fear memory (Goshen et al., 2011). These findings suggest the involvement of the hippocampus in the recall of both new and remote memories. In this context, place cell stability, which has been shown to require the same molecular pathways as memory consolidation and cellular models of synaptic plasticity (Kentros et al., 1998; Rotenberg et al., 2000; Agnihotri et al., 2004), may lead to increases in synaptic efficacy that could be important for the retrieval of recent as well as remote fearful memories. It is possible that emotional memories are remembered with greater detail than neutral ones (Schmidt et al., 2011) due to the formation of stable representations in the hippocampus of the contexts in which these memories occur.

Our findings suggest that changing the emotional valence of the context is sufficient to alter the hippocampal representation of that context. In a study by Oler et al. (2008) using a discrimination task, minimal place cell remapping was observed in a particular trajectory made "unsafe " by the presentation of a tone previously associated with shock. This led the authors to suggest that changes in trajectory and not emotional or behavioral states within a context were the main source of short-term remapping observed in their study as well as several other studies involving changes in task contingencies (Markus et al., 1995; Ferbinteanu and Shapiro, 2003; Moita et al., 2004; Smith and Mizumori, 2006). However, in the study by Oler et al., fear was associated with a tone and not the environment itself. In fact, it has been shown that place cell remapping occurs only after contextual and not cued fear conditioning (Moita et al., 2003, 2004). Here we show that when fear is directly associated with a context, remapping occurs both during and directly after a fearful encounter. In addition, the new representation of the context is stable in several long-term memory retrieval tests, suggesting that the short-term remapping observed is not merely a result of changes in an animal's trajectory through a context. Our data indicate that place cells do in fact remap in response to changes in the emotional valence of a context, and that a stable long-term memory trace of a fearful environment is formed in the hippocampus.

In summary, our findings imply that a one-time change in the emotional valence of a context is sufficient to create a novel representation of that context that is memorable in the long term. These results provide valuable information toward understanding the pervasive quality of emotional memories and may have important implications for anxiety-related psychopathologies.

\section{References}

Agnihotri NT, Hawkins RD, Kandel ER, Kentros C (2004) The long-term stability of new hippocampal place fields requires new protein synthesis. Proc Natl Acad Sci U S A 101:3656-3661.

Anderson MI, Jeffery KJ (2003) Heterogeneous modulation of place cell firing by changes in context. J Neurosci 23:8827-8835.

Bekinschtein P, Cammarota M, Igaz LM, Bevilaqua LR, Izquierdo I, Medina JH (2007) Persistence of long-term memory storage requires a late protein synthesis- and BDNF- dependent phase in the hippocampus. Neuron 53:261-277.

Blanchard RJ, Blanchard DC (1969) Crouching as an index of fear. J Comp Physiol Psychol 67:370-375.

Bourtchouladze R, Abel T, Berman N, Gordon R, Lapidus K, Kandel ER (1998) Different training procedures recruit either one or two critical periods for contextual memory consolidation, each of which requires protein synthesis and PKA. Learn Mem 5:365-374.

Colgin LL, Moser EI, Moser MB (2008) Understanding memory through hippocampal remapping. Trends Neurosci 31:469-477.

Deshmukh SS, Knierim JJ (2011) Representation of non-spatial and spatial information in the lateral entorhinal cortex. Front Behav Neurosci 5:69.

Dielenberg RA, McGregor IS (2001) Defensive behavior in rats towards predatory odors: a review. Neurosci Biobehav Rev 25:597-609.

Dudai Y (2004) The neurobiology of consolidations, or, how stable is the engram? Annu Rev Psychol 55:51-86.

Eilam D (2005) Die hard: a blend of freezing and fleeing as a dynamic defense-implications for the control of defensive behavior. Neurosci Biobehav Rev 29:1181-1191.

Faraway JJ (2006) Extending the linear model with R: generalized linear, mixed effects and nonparametric regression models. Boca Raton, FL: CRC/Chapman and Hall.

Ferbinteanu J, Shapiro ML (2003) Prospective and retrospective memory coding in the hippocampus. Neuron 40:1227-1239.

Frankland PW, Bontempi B (2005) The organization of recent and remote memories. Nat Rev Neurosci 6:119-130.

Goldstein H (2010) Multilevel statistical models, Ed 4. Chichester, UK: Wiley.

Goshen I, Brodsky M, Prakash R, Wallace J, Gradinaru V, Ramakrishnan C, Deisseroth K (2011) Dynamics of retrieval strategies for remote memories. Cell 147:678-689.

Gothard KM, Skaggs WE, Moore KM, McNaughton BL (1996) Binding of hippocampal CA1 neural activity to multiple reference frames in a landmark-based navigation task. J Neurosci 16:823-835.

Grant EW, Mackintosh JH (1963) A comparison of the social postures of some common laboratory rodents. Behaviour 21:246-259.

Harris KD, Hirase H, Leinekugel X, Henze DA, Buzsáki G (2001) Temporal interaction between single spikes and complex spike bursts in hippocampal pyramidal cells. Neuron 32:141-149.

Hoscheidt SM, Nadel L, Payne J, Ryan L (2010) Hippocampal activation during retrieval of spatial context from episodic and semantic memory. Behav Brain Res 212:121-132.

Huxter J, Burgess N, O’Keefe J (2003) Independent rate and temporal coding in hippocampal pyramidal cells. Nature 425:828-832.

Kentros C, Hargreaves E, Hawkins RD, Kandel ER, Shapiro M, Muller RV (1998) Abolition of long-term stability of new hippocampal place cell maps by NMDA receptor blockade. Science 280:2121-2126.

Kentros CG, Agnihotri NT, Streater S, Hawkins RD, Kandel ER (2004) In- 
creased attention to spatial context increases both place field stability and spatial memory. Neuron 42:283-295.

Kim JJ, Fanselow MS (1992) Modality-specific retrograde amnesia of fear. Science 256:675-677.

Kim JJ, Rison RA, Fanselow MS (1993) Effects of amygdala, hippocampus, and periaqueductal gray lesions on short- and long-term contextual fear. Behav Neurosci 107:1093-1098.

Knierim JJ (2002) Dynamic interactions between local surface cues, distal landmarks, and intrinsic circuitry in hippocampal place cells. J Neurosci 22:6254-6264.

Knierim JJ (2003) Hippocampus and memory. Can we have our place and fear it too? Neuron 37:372-374.

Markus EJ, Qin YL, Leonard B, Skaggs WE, McNaughton BL, Barnes CA (1995) Interactions between location and task affect the spatial and directional firing of hippocampal neurons. J Neurosci 15:7079-7094.

Maxwell SE, Delaney HD (2004) Designing experiments and analyzing data, Ed 2. Hillsdale, NJ: Lawrence Erlbaum Associates.

McCulloch CE, Searle SR (2001) Generalized, linear, and mixed models. New York: Wiley.

McGaugh JL (1966) Time-dependent processes in memory storage. Science 153:1351-1358.

McHugh TJ, Jones MW, Quinn JJ, Balthasar N, Coppari R, Elmquist JK, Lowell BB, Fanselow MS, Wilson MA, Tonegawa S (2007) Dentate gyrus NMDA receptors mediate rapid pattern separation in the hippocampal network. Science 317:94-99.

Moita MA, Rosis S, Zhou Y, LeDoux JE, Blair HT (2003) Hippocampal place cells acquire location-specific responses to the conditioned stimulus during auditory fear conditioning. Neuron 37:485-497.

Moita MA, Rosis S, Zhou Y, LeDoux JE, Blair HT (2004) Putting fear in its place: remapping of hippocampal place cells during fear conditioning. J Neurosci 24:7015-7023.

Muzzio IA, Kentros C, Kandel E (2009a) What is remembered? Role of attention on the encoding and retrieval of hippocampal representations. J Physiol 587:2837-2854.

Muzzio IA, Levita L, Kulkarni J, Monaco J, Kentros C, Stead M, Abbott LF, Kandel ER (2009b) Attention enhances the retrieval and stability of visuospatial and olfactory representations in the dorsal hippocampus. PLoS Biol 7:e1000140.

O’Keefe J, Dostrovsky J (1971) The hippocampus as a spatial map. Preliminary evidence from unit activity in the freely-moving rat. Brain Res 34:171-175.

O'Keefe J, Nadel L (1978) The hippocampus as a cognitive map. Oxford: Oxford UP.

Oler JA, Penley SC, Sava S, Markus EJ (2008) Does the dorsal hippocampus process navigational routes or behavioral context? A single-unit analysis. Eur J Neurosci 28:802-812.

Pavlov IP (1927) Conditioned reflexes. London: Oxford UP.

Phillips RG, LeDoux JE (1992) Differential contribution of amygdala and hippocampus to cued and contextual fear conditioning. Behav Neurosci 106:274-285.
Powers MM, Clark G (1955) An evaluation of cresyl echt violet acetate as a Nissl stain. Stain Technol 30:83-88.

Quirk GJ, Muller RU, Kubie JL (1990) The firing of hippocampal place cells in the dark depends on the rat's recent experience. J Neurosci 10:2008-2017.

Ranck JB Jr (1973) Studies on single neurons in dorsal hippocampal formation and septum in unrestrained rats. I. Behavioral correlates and firing repertoires. Exp Neurol 41:461-531.

Raudenbush SW, Bryk AS (2002) Hierarchical linear models: applications and data analysis methods, Ed 2. Thousand Oaks, CA: Sage.

Rosen JB, Pagani JH, Rolla KL, Davis C (2008) Analysis of behavioral constraints and the neuroanatomy of fear to the predator odor trimethylthiazoline: a model for animal phobias. Neurosci Biobehav Rev 32:1267-1276

Rotenberg A, Abel T, Hawkins RD, Kandel ER, Muller RU (2000) Parallel instabilities of long-term potentiation, place cells, and learning caused by decreased protein kinase A activity. J Neurosci 20:8096-8102.

Schmidt K, Patnaik P, Kensinger EA (2011) Emotion's influence on memory for spatial and temporal context. Cogn Emot 25:229-243.

Schmitzer-Torbert N, Jackson J, Henze D, Harris K, Redish AD (2005) Quantitative measures of cluster quality for use in extracellular recordings. Neuroscience 131:1-11.

Smith DM, Mizumori SJ (2006) Learning-related development of contextspecific neuronal responses to places and events: the hippocampal role in context processing. J Neurosci 26:3154-3163.

Squire LR, Wixted JT (2011) The cognitive neuroscience of human memory since H.M. Annu Rev Neurosci 34:259-288.

Takahashi LK, Hubbard DT, Lee I, Dar Y, Sipes SM (2007) Predator odorinduced conditioned fear involves the basolateral and medial amygdala. Behav Neurosci 121:100-110.

Tanila H, Shapiro ML, Eichenbaum H (1997) Discordance of spatial representation in ensembles of hippocampal place cells. Hippocampus 7:613-623.

Ulrich R (1966) Pain as a cause of aggression. Am Zool 6:643-661.

Verbeke G, Molenberghs G (2000) Linear mixed models for longitudinal data. New York: Springer.

Wiener SI, Paul CA, Eichenbaum H (1989) Spatial and behavioral correlates of hippocampal neuronal activity. J Neurosci 9:2737-2763.

Wood ER, Dudchenko PA, Eichenbaum H (1999) The global record of memory in hippocampal neuronal activity. Nature 397:613-616.

Young SL, Bohenek DL, Fanselow MS (1994) NMDA processes mediate anterograde amnesia of contextual fear conditioning induced by hippocampal damage: immunization against amnesia by context preexposure. Behav Neurosci 108:19-29.

Zinyuk L, Kubik S, Kaminsky Y, Fenton AA, Bures J (2000) Understanding hippocampal activity by using purposeful behavior: place navigation induces place cell discharge in both task-relevant and task-irrelevant spatial reference frames. Proc Natl Acad Sci U S A 97:3771-3776. 